Article

\title{
Sulfuric Acid Leaching of Altered Ilmenite Using Thermal, Mechanical and Chemical Activation
}

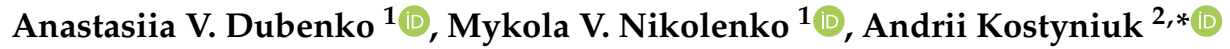 \\ and Blaž Likozar 2,3 (D) \\ 1 Faculty of Chemical Technologies and Ecology, Ukrainian State University of Chemical Technology, \\ Gagarin Avenue 8, 49005 Dnipro, Ukraine; anastasiia.dubenko@gmail.com (A.V.D.); \\ n_nikolenko@ukr.net (M.V.N.) \\ 2 Department of Catalysis and Chemical Reaction Engineering, National Institute of Chemistry, Hajdrihova 19, \\ 1001 Ljubljana, Slovenia; blaz.likozar@ki.si \\ 3 Faculty of Chemistry and Chemical Technology, University of Ljubljana, Večna pot 113, \\ 1000 Ljubljana, Slovenia \\ * Correspondence: andrii.kostyniuk@ki.si
}

Received: 12 May 2020; Accepted: 10 June 2020; Published: 13 June 2020

\begin{abstract}
The kinetics of the sulfuric acid leaching of altered ilmenite, mechanisms, and process intensification methods were studied. The effect of changing the chemical composition during grinding was determined. The content of ilmenite and pseudorutile decreased from $5.3 \%$ to $3.1 \%$ and from $90.2 \%$ to $63.1 \%$, respectively. Rutile increased from $4.5 \%$ to $28.7 \%$, while a pseudobrookite new phase appeared in the amount of $5.1 \%$ after $2 \mathrm{~h}$ of grinding. It was found that the modification of raw material by sulfuric acid led to the increase of the decomposition rate, and at the same time, decreased when the ore was utilized due to an increase of insoluble $\mathrm{TiO}_{2}$ content. Isothermal conditions were evaluated with $\mathrm{H}_{2} \mathrm{SO}_{4}$ concentration varying from 50 to $96 \%$. The data obtained were described with the approximation of the contracting sphere model. It was shown for the first time that $\mathrm{H}_{2} \mathrm{SO}_{4}$ $>85 \mathrm{wt} \%$ causes a sharp constant decrease of titanium. Correlating these phenomena allows for the consideration of $\mathrm{H}_{2} \mathrm{SO}_{4} \cdot \mathrm{H}_{2} \mathrm{O}$ as reagents, rather than $\mathrm{H}_{2} \mathrm{SO}_{4}$ molecules. It was experimentally proven that at a temperature above $190^{\circ} \mathrm{C}$, the Ti leaching degree dropped, which is explained by the formation of polymerized $\mathrm{TiOSO}_{4}$. Finally, it was shown that adding $\mathrm{NaF}$ reduced the activation energy to $45 \mathrm{~kJ} / \mathrm{mol}$.
\end{abstract}

Keywords: altered ilmenite; sulfuric acid; ore chemical activation; ore mechanical activation; leaching process; rutile/pseudobrookite/pseudorutile; mathematical model simulations; rate constant equation; activation energy barrier

\section{Introduction}

Titanium dioxide is one of the most important products of an inorganic synthesis utilized in the manufacture of paints, paper, plastics, food additives, and cosmetics. The sulfate method, the chloride method [1-4], and the fluoride method of ilmenite ores leaching [5-7] are widely used in the manufacture of titanium dioxide. The chloride method is utilized on an industrial scale in Asia and Africa [8]. This method requires significant energy costs for the production of hydrochloric acid, and at the same time, the method is characterized by high emissions of gaseous pollutants. The sulfuric acid method of the leaching of titanium-bearing ores is devoid of these disadvantages [9,10]. Currently, the volume of acid wastes has sharply decreased after the deep modernization of a number of industrial plants using sulfuric acid leaching of titanium-containing ores, and this method again has become considered as the most advanced [11,12]. Analysis of the literature shows that work is still ongoing 
to find further ways to modernize this method. The solution to this problem is undertaken in three directions using mechanical, thermal, and chemical activation.

Plenty of works have shown that the mechanical activation of the raw materials significantly increases the dissolution rate of solid minerals [13-18]. Phase composition changes during the mechanical dispersion process under atmospheric conditions have been observed by many authors. For instance, it was suggested that ilmenite gradually turned into pseudorutile $\left(\mathrm{Fe}_{2} \mathrm{Ti}_{3} \mathrm{O}_{9}\right)$ during the milling process in the air $[15,18]$. Furthermore, the authors found that some grains of ilmenite were turned into leucoxene during grinding [19]. It was concluded that the altered ilmenite (leucoxene) located into cracks and/or on the surface of ilmenite grains existed in an amorphous state after grinding the raw materials. The formation of defective crystalline structure, oxidation of ferrous iron, and the increase in the specific surface of powders due to the decrease in the size of ore particles are the main reasons for this effect [20].

A method for the grinding of raw materials in the liquid conditions where the raw material was ground in sulfuric acid and water has been shown [10]. A larger quantity of the active centers that form on the surface of the particles is established during grinding in an acidic medium, which accelerates the further leaching process. The grinding of raw materials in an aqueous medium made ilmenite more active, and the milled samples showed lower activation energies during the leaching process. However, a change in the phase composition of the raw material during grinding was not observed [21,22].

There are lots of data presented for ilmenite concentrates that have not undergone the leukoxenization process. Additionally, we can see that the presented results are contradictory, which means that it is of interest to research the effect of the mechanical activation of altered ilmenite on the degree of extraction of the target component.

The chemical activation of raw materials with sulfuric acid solutions is also debated today [23-26]. The effect of the concentration and modulus of sulfuric acid on the decomposition of ilmenite was investigated repeatedly by $[9,10,14,17,22,27-39]$. The extraction degree of titanium into the solution increased with increasing concentrations of sulfuric acid and it was first found by Han [27]. However, when $\mathrm{H}_{2} \mathrm{SO}_{4}$ solutions were utilized with a concentration above $14 \mathrm{M}$, the reducing effect of the efficiency of the leaching process was observed. Similar results were obtained when the authors studied the sulfuric acid leaching of ilmenite with the composition of $51 \% \mathrm{TiO}_{2}, 36.8 \% \mathrm{FeO}$, and $4.97 \%$ $\mathrm{Fe}_{2} \mathrm{O}_{3}$ [17]. It was found that with an increase in acid concentration up to $14 \mathrm{M}(79.8 \mathrm{wt} \%)$, the rate of the process increased. However, the process rate quickly decreased using higher concentrations of $\mathrm{H}_{2} \mathrm{SO}_{4}$. According to various authors, this maximum is achieved with the concentration of sulfuric acid at $6 \mathrm{M}$ [36], $9 \mathrm{M}$ [10,31], $10 \mathrm{M}$ [9], $15 \mathrm{M}$ [30], 15.5 M [28,34], and $17 \mathrm{M}$ [27]. This effect of the sulfuric acid concentration was explained by the authors as symbatic change in the concentration of hydrogen ions in sulfuric acid solutions [27]. Although, according to their data, the maximum $\mathrm{H}+$ content was reached much earlier when $11 \mathrm{M}$ sulfuric acid solutions were utilized. The reduction of the ionization of sulfuric acid molecules of almost 1.3 times in $14 \mathrm{M}$ sulfuric acid solution when compared with $11 \mathrm{M} \mathrm{H}_{2} \mathrm{SO}_{4}$ has been reported [30]. Once more, the optimal range of the $\mathrm{H}_{2} \mathrm{SO}_{4}$ concentration for the leaching process was $14-16 \mathrm{M}[37,38]$. These results were obtained based on measuring the thermal power of the leaching process such as heat generation during the leaching process. It should be noted that the leaching time is significantly different for each experiment. In addition, the optimal mass module of the reaction mixture is different for each sulfuric acid leaching: $\mathrm{H}_{2} \mathrm{SO}_{4}: \mathrm{FeTiO}_{3}=2.7: 1$ [30], $\mathrm{H}_{2} \mathrm{SO}_{4}: \mathrm{FeTiO}_{3}=6: 1$ [34], and $\mathrm{H}_{2} \mathrm{SO}_{4}: \mathrm{FeTiO}_{3}=9: 1$ [35].

One of the alternative methods of leaching the titanium-containing materials is the fluoride method. There are two main groups of methods for processing ores using fluorine compounds such as the thermal and hydrometallurgical methods $[40,41]$. The latter is becoming widely used since this method is very prospective due to the possibility of recycling the main components [7,42-44]. Nowadays, hydrometallurgical methods for the processing of various concentrates are at the initial stage of their development [5,6,45-47]. The most common fluorinating agents are $\mathrm{F}_{2}[44], \mathrm{H}_{2} \mathrm{SiF}_{6}[47,48]$, 
and HF [49,50]. However, ammonium fluoride and ammonium hydrodifluoride are increasingly used in non-aqueous (in "dry") and hydrometallurgical methods [50-55]. The initial processing of the raw material can be carried out at sufficiently low temperatures, which leads to lower energy consumption compared to the "dry" method. The main disadvantage of the fluoride method is the large excess of the leaching reagent. This requirement is due to the consumption of fluoride ions in the reaction with iron (in ilmenite), a large amount of waste in the form of pulps and solutions as well as a greater number of technological stages when compared to the sulfate method.

The differences in the optimal conditions for the sulfuric acid leaching of titanium-containing ores can be explained by the fact that the obtained ores from the different deposits are various in its mineralogical composition and, accordingly, in chemical properties.

One of the main parameters of the leaching is temperature. In the course of researching the thermal activation of raw materials, it was found that the degree of titanium extraction increased with increasing temperature in the leaching process [10,22,32,34,35,56-63]. This dependence was observed up to certain temperatures. According to [62], the titanium extraction degree rapidly increased as the temperature rose and reached the maximum at $160{ }^{\circ} \mathrm{C}$ in the leaching of the titanium-bearing materials. A titanium salt undergoes hydrolysis in the solution at higher temperatures, which leads to the decrease of its content in the solution. The agglomerates formed in the reaction mixture at the temperature of $200^{\circ} \mathrm{C}$, which could not be leached. The authors [62] suggest that such aggregates are the product of the polymerization of hydrolysis forms of titanium. The formation of agglomerates that were insoluble in sulfuric acid $(5 \%)$ was observed $[27,28]$. The experiments on the ilmenite leaching were carried out in the acid solutions of more than $80 \%$ and at the temperature of $200{ }^{\circ} \mathrm{C}$. In the authors' opinion, such agglomerates are insoluble in concentrated sulfuric acid. These agglomerates form as a result of blocking the surface of unreacted ore particles by the precipitation of titanium and iron sulfates. The optimum conditions for the decomposition of altered ilmenite are the temperature of $200{ }^{\circ} \mathrm{C}$ and sulfuric acid concentration of $88 \mathrm{wt} \%$ [61]. However, not many research works have been devoted to the leaching of altered ilmenite [64]. Therefore, more detailed study in this direction is necessary.

The values of the activation energies are important data to determine a mechanism of the leaching processes. The literature provides quite different values of activation energies for the sulfuric acid leaching of ilmenite and its altered form. For instance, activation energies in the range of $28-48 \mathrm{~kJ} / \mathrm{mol}$ was obtained [63-66]. In addition, the next values were obtained in different ranges such as 75.0 [27], 72.6 [62], and $64.4 \mathrm{~kJ} / \mathrm{mol}[56]$.

Furthermore, values of activation energies in the range of 52-62 kJ/mol [21] and 80-100 kJ/mol were obtained [24]. Apparently, such a difference in the activation energies can be explained by the difference in the chemical compositions of the researched ilmenite ores. It would be interesting to determine the activation energy values for the sulfuric acid leaching of altered ilmenite.

Ukraine has the vast reserves of ilmenite consisting of 40 explored alluvial and primary mine deposits, 16 of these deposits are currently used in industrial mining and enrichment. The main ore reserves are concentrated in the Malyshevske and Irshanske deposits. The most difficult problem is to process altered ilmenites such as ilmenite from the Malyshevske deposit. The enrichment of ilmenite with titanium occurs due to the oxidation of ferrous iron and its displacement with long-term weathering of the ore (so-called leukoxenization process). The titanium content calculated on titanium dioxide can exceed $65 \mathrm{wt} \%$ in such altered ilmenites. This chemical composition makes such a raw material hardly-suitable in sulfuric acid processing for the production of titanium dioxide. This fact leads to a low degree of using raw materials, decreasing the overall production efficiency and relatively low quality of the product. The reasons for the low efficiency of using altered ilmenite can be explained by the presence of a rutile ballast, which practically does not dissolve in sulfuric acid under industrial conditions of leaching. 
Thus, the current work aims to select the optimal conditions for the sulfuric acid leaching of altered ilmenite, allowing the intensification of the sulfuric leaching process by means of the mechanical, chemical, and thermal activation of raw materials.

\section{Materials and Methods}

\subsection{Chemical Composition of Ilmenite Concentrate}

The ilmenite concentrate from the Malyshevske deposit (Ukraine) was used in the experiments. Grinding of ilmenite concentrate was carried out in a drum mill at room temperature under the following conditions: sample weight of $100 \mathrm{~g}$, a mass of cylindrical grinding bodies made of zirconium ceramics weighing $3 \mathrm{~kg}$ and a size of $40 \times 40 \mathrm{~mm}$, the container volume was $2 \mathrm{~L}$, the rotation speed was $600 \mathrm{rpm}$, and the grinding process was dry.

The studies of the chemical composition of ilmenite concentrate from the Malyshevske deposit (Ukraine) were carried out by $\mathrm{x}$-ray energy dispersive analysis. Element percentages are reported with bars, which present the average values from the obtained results for the sample (Table 1). It was found that the molar ratio of Ti/Fe exceeded the stoichiometric ratio 2.4 times. This fact allows us to conclude that the ilmenite of the Malyshevske deposit is significantly altered.

Table 1. The chemical composition of ilmenite concentrate from the Malyshevske deposit.

\begin{tabular}{cccccccccccc}
\hline Element & $\mathbf{T i}$ & $\mathbf{F e}$ & $\mathbf{M g}$ & $\mathbf{M n}$ & $\mathbf{C r}$ & $\mathbf{P}$ & $\mathbf{V}$ & $\mathbf{A l}$ & $\mathrm{Si}$ & $\mathbf{C a}$ & $\mathbf{O}$ \\
\hline $\boldsymbol{\omega}, \mathbf{w t} \%$ & 41.0 & 19.9 & 0.540 & 0.190 & 0.100 & 0.080 & 0.120 & 0.420 & 0.370 & 0.040 & 37.2 \\
\hline
\end{tabular}

\subsection{Experimental Methods and Procedures}

Microscopy investigations were performed using an optical microscope NU-2 (Carl Zeiss, Jena, Germany) and scanning electron microscope JEOL JSM-6510 with energy dispersive spectrometer INCA Energy X-Max. X-ray phase analysis was performed using a diffractometer PANalytical X'Pert Pro (Almelo, The Netherlands) in monochromatic $\mathrm{Cu}-\mathrm{K} \alpha 1$ emission with a wavelength of $\mathrm{K} \alpha 1=1.54056 \AA$. This was equipped with a linear correction system with a long wavelength of $K \alpha 2=1.54433 \AA$ (Universite du Maine, Le Mans, France). To analyze the diffraction patterns, the Match!2 software package was used. This allowed us to make a qualitative (using standard crystallographic databases) and quantitative (using the iterative Rietveld refinement method) identification of diffraction patterns.

The leaching experiments were carried out with a mass ratio of ilmenite:sulfuric acid $=1: 2$, the initial concentration of sulfuric acid was $50-96 \mathrm{wt} \%$, and the temperature was $100-200{ }^{\circ} \mathrm{C}$ without stirring. After leaching, the reaction mixture was quantitatively transferred to a volumetric flask, washing it with a solution of $5 \%$ sulfuric acid to prevent the hydrolysis of titanium compounds. Thereafter, the suspension was filtered under vacuum using the «blue ribbon» filters. The titanium content in the filtrate was determined spectrophotometrically in the form of a peroxide complex at a wavelength of $410 \mathrm{~nm}$ using an SF-46 spectrophotometer. The presence of iron was masked with phosphoric acid.

We considered rutile as a ballast substance due to its insolubility in sulfuric acid. Therefore, we did not take rutile into account to calculate the degree of ilmenite concentrate leaching. The degree of titanium recovery was calculated as the ratio of the amount of titanium(IV) transferred to the solution to its initial content in the ilmenite concentrate and in the composition of pseudorutile, pseudobrookite, and ilmenite, which was $45 \%$ based on $\mathrm{TiO}_{2}$.

Experiments on sulfuric acid leaching with the participation of fluoride ions were carried out in a laboratory high-pressure reactor RVD-2-700 with a Teflon coating at the processing time of $0.5-1 \mathrm{~h}$ without stirring. The module mass of $\left(\mathrm{FeTiO}_{3}: \mathrm{NaF}\right)$ was varied: (1:0), (1:0.25), (1:0.5), (1:0.75), (1:1). The concentration of $\mathrm{H}_{2} \mathrm{SO}_{4}$ was $85 \mathrm{wt} \%$, and the reaction temperature was $100{ }^{\circ} \mathrm{C}$. NaF was utilized as the fluorinating agent. The titanium content in the filtrate was also determined spectrophotometrically 
after the suspension was filtered and evaporated from the traces of fluoride. All the reagents used for the leaching and chemical analysis were of analytical grade ("Reachem" supplier).

\section{Results and Discussion}

\subsection{Mechanical Activation of the Raw Material}

A histogram of the ilmenite particle size distribution is presented in Figure 1. The most probable particle size was $164 \mu \mathrm{m}(163.8 \mu \mathrm{m}$, at half-width of the distribution curve of $27.5 \mu \mathrm{m})$ before grinding. The particle size decreased after grinding for $2 \mathrm{~h}$ in a drum mill and the most probable particle size was $11 \mu \mathrm{m}(10.8 \mu \mathrm{m}$, at half-width of the distribution curve of $2.5 \mu \mathrm{m})$ [67].

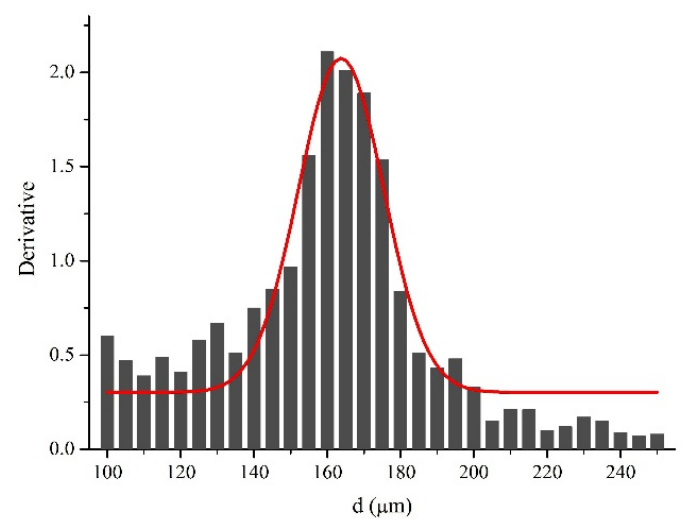

(a)

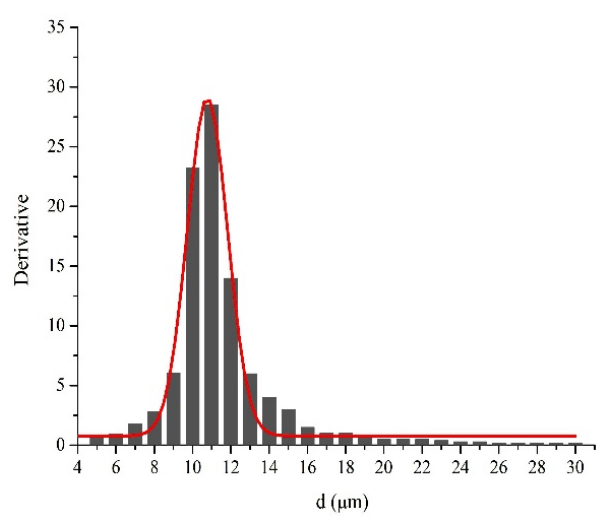

(b)

Figure 1. The histograms of the distribution of ilmenite particles in size: (a) before grinding; (b) after grinding for $2 \mathrm{~h}$.

The experiments were carried out with various fractions of ground ore to analyze the effect of the mechanical activation of ilmenite concentrate on its dissolution rate in sulfuric acid. It was found that ilmenite concentrate without grinding practically did not dissolve in $94 \%$ sulfuric acid, even when the temperature was raised up to $200^{\circ} \mathrm{C}$. In addition, it was established that the leaching process intensified and the reaction mixture solidified in $3 \mathrm{~min}$ after adding a portion of ilmenite concentrate to the acid solution with a fraction of $40 \mu \mathrm{m}$ (for example Figures 4 and 5 in Section 3.2). It is known that this solidification is explained by the achievement of saturated concentrations of the decomposition products of ilmenite ores such as iron and titanium sulfates.

As it is widely known, the rate of a heterogeneous chemical process is directly proportional to the specific surface area of particles of a solid reagent. The reactivity of ore particles can also change due to an increase in the degree of defect of its crystal lattices or changing phase composition in the grinding process. The $\mathrm{x}$-ray powder diffraction study was carried out to define the effect of the grinding process on the phase composition of the ilmenite concentrate. The ore sample was ground for $2 \mathrm{~h}$. Figure 2 shows the diffraction pattern of the obtained data for the initial (not crushed) sample of ilmenite concentrate and the sample subjected to grinding for $2 \mathrm{~h}$.

According to the data in Figure 2, the phases of ilmenite $\mathrm{FeTiO}_{3}$ (PCPDFWIN 00-071-1140), rutile $\mathrm{TiO}_{2}$ (00-075-1757), and pseudorutile $\mathrm{Fe}_{2} \mathrm{Ti}_{3} \mathrm{O}_{9}$ (00-019-0635) were observed both in the initial sample and in the material after grinding. However, the relative content of these phases changed after grinding.

The quantitative $x$-ray phase analysis showed that the content of ilmenite $(5.3 \%)$, rutile $(4.5 \%)$, and pseudorutile (90.2\%) in the studied sample of the ilmenite concentrate.

While the particle size decreased, the content of ilmenite and pseudorutile decreased, and the rutile content was increased, as shown with a quantitative analysis of the diffraction patterns in MATCH!2 software using the PCPDFWIN database (Figure 3). The content of ilmenite and pseudorutile was decreased to 3.1 and $63.1 \%$, respectively, while the content of rutile was increased to $28.7 \%$ after 
grinding for $2 \mathrm{~h}$ (particle size $<40 \mu \mathrm{m}$ ). Furthermore, the additional reflections appeared in the diffraction patterns, which were identified as the reflections of pseudobrookite $\mathrm{Fe}_{2} \mathrm{TiO}_{5}(00-041-1432)$ in the amount of $5.1 \%$.

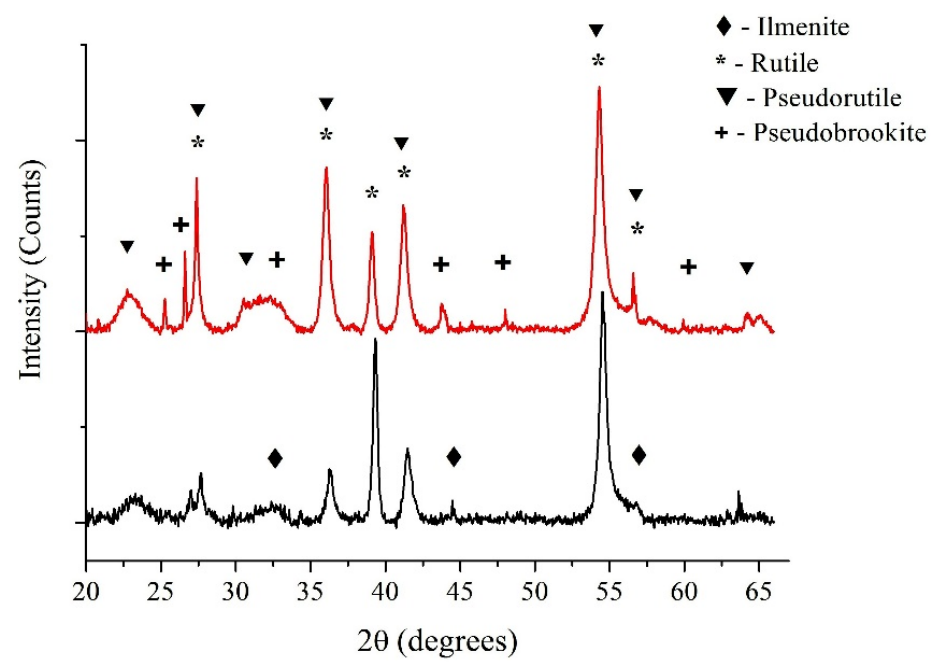

Figure 2. Diffraction patterns of ilmenite concentrate from the Malyshevske deposit before grinding (black line) and after $2 \mathrm{~h}$ of grinding (red line).

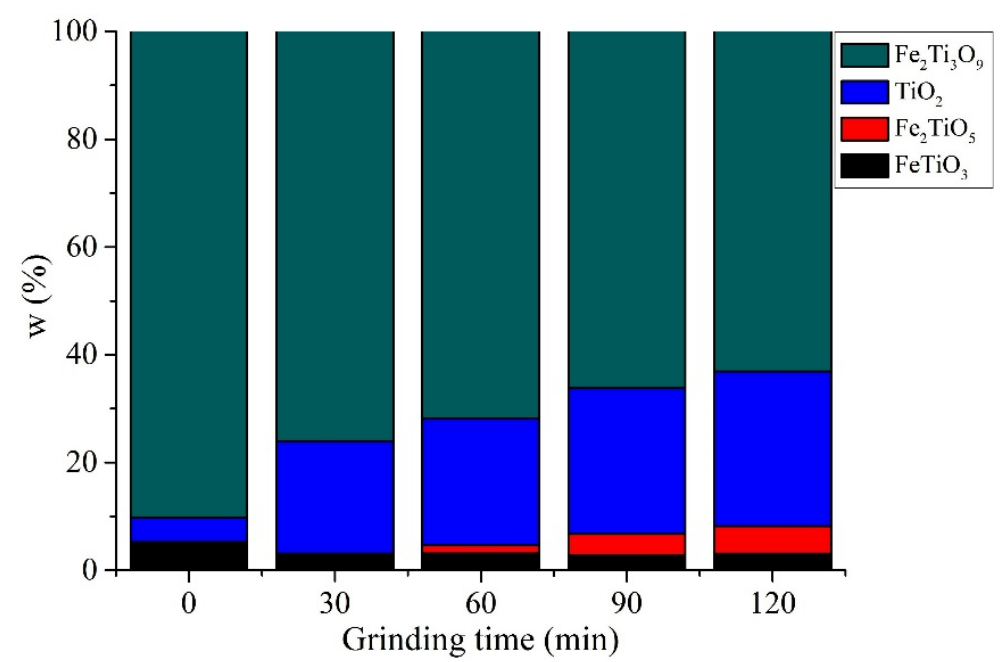

Figure 3. The mass percentage change of the main phase fraction of the ilmenite concentrate from the Malyshevske deposit, depending on the particle size after grinding for $2 \mathrm{~h}$.

The mechanical activation of altered ilmenite not only had a positive effect of accelerating the titanium ore leaching due to an increase in the specific surface area and an increase in the reactivity of ore particles, but a negative effect also occurs due to an increase in the content of the $\mathrm{TiO}_{2}$ rutile phase, which is inert to acid decomposition, as can be seen in the results of the investigations. Analysis of the diffraction patterns of the ground ilmenite concentrate samples showed that the concentrate phase composition underwent significant changes (Figures 1 and 3) during the grinding process. It was found that the content of ilmenite and pseudorutile decreased, and rutile increased with decreasing particle size.

The possibility of the mechanochemical transformation of solids in the grinding process was proven and can be explained by the breaking of chemical bonds in places of the mechanical deformation 
of particles $[15,18]$. It was concluded that the change in the phase composition of ilmenite ores occurred due to the oxidation of divalent iron during grinding:

$$
\begin{gathered}
2 \mathrm{FeTiO}_{3}+0.5 \mathrm{O}_{2}=2 \mathrm{TiO}_{2}+\mathrm{Fe}_{2} \mathrm{O}_{3} \\
6 \mathrm{FeTiO}_{3}+3 / 2 \mathrm{O}_{2}=2 \mathrm{Fe}_{2} \mathrm{Ti}_{3} \mathrm{O}_{9}+\mathrm{Fe}_{2} \mathrm{O}_{3}
\end{gathered}
$$

Iron oxide is formed in both reactions, but this fact is not confirmed by XRD study. It was explained by the formation of the $\mathrm{Fe}_{2} \mathrm{O}_{3}$ phase in an amorphous form, which does not allow identifying its presence by x-ray diffraction [15].

The most rapid changes in the composition of the studied ilmenite concentrate were noted to occur in the first $30 \mathrm{~min}$ (Figure 3). These changes were not connected with the oxidative decomposition of ilmenite, but connected to the decomposition of pseudorutile. Therefore, reactions (1) and (2) cannot explain all the observed changes in the composition of ilmenite ore of the Malyshevske deposit. The possibility of the next reactions can explain the reasons of the decrease in the pseudorutile content and pseudobrookite formation:

$$
\mathrm{Fe}_{2} \mathrm{Ti}_{3} \mathrm{O}_{9}=\mathrm{Fe}_{2} \mathrm{TiO}_{5}+2 \mathrm{TiO}_{2}
$$

It was reported that pseudorutile is formed during grinding of $\mathrm{FeTiO}_{3}$ in the air, but its further conversion to pseudobrookite does not occur, although reaction (3) is thermodynamically possible [15]. In contrast to these data, our study showed that the metastable phase of $\mathrm{Fe}_{2} \mathrm{Ti}_{3} \mathrm{O}_{9}$ can be destroyed with the formation of more stable forms of $\mathrm{Fe}_{2} \mathrm{TiO}_{5}$ and $\mathrm{TiO}_{2}$ at mechanical activation. A discrepancy was observed in the material balance with a decrease in the pseudorutile content of $27 \%$, where only $5.1 \%$ of pseudobrookite formed. This can be explained by most of the $\mathrm{Fe}_{2} \mathrm{TiO}_{5}$ phase remaining in the amorphous state such as iron oxide.

The processes of obtaining pseudobrookite not only as a result of the decomposition reaction but also as a result of synthesis involving the $\mathrm{Fe}_{2} \mathrm{O}_{3}$ phase can be described as $[15,18]$ :

$$
\begin{gathered}
\mathrm{Fe}_{2} \mathrm{O}_{3}+\mathrm{TiO}_{2}=\mathrm{Fe}_{2} \mathrm{TiO}_{5} \\
\mathrm{Fe}_{2} \mathrm{Ti}_{3} \mathrm{O}_{9}+2 \mathrm{Fe}_{2} \mathrm{O}_{3}=3 \mathrm{Fe}_{2} \mathrm{TiO}_{5}
\end{gathered}
$$

It is known that carrying out these reactions at a noticeable rate is possible only at high temperatures. Therefore, the probability of the implementation of reactions (4) and (5) as a result of mechanochemical activation is rather low. This conclusion is well confirmed by the obtained experimental data. The observed decrease in the ilmenite content after $120 \mathrm{~min}$ of grinding was only $2 \%$, while the amount of pseudobrookite was $5.1 \%$, which was detected by the XRD method.

\subsection{Influence of Sulfuric Acid Concentration on the Leaching Process}

The influence of the concentration of sulfuric acid on the titanium leaching was considered by us as a method of chemical activation (intensification) of the decomposition of the ilmenite ore. Furthermore, the unusual nature of the effect of the concentration of sulfuric acid on the efficiency of titanium leaching has been repeatedly noted $[10,17,22]$.

Figures 4 and 5 show the results of our kinetic studies using solutions of sulfuric acid with a concentration of 50, 60, 8085,90 and $96 \mathrm{wt} \%$ [68]. The experiments were carried out in isothermal conditions at a temperature of $100^{\circ} \mathrm{C}$. The titanium leaching degree was calculated on the total titanium content in the ilmenite concentrate.

The solidification of the reaction mixture observed at reaching the $15 \%$ degree of titanium leaching (the dashed line in Figures 4 and 5) can be explained by the achievement of saturated concentrations of the decomposition products of ilmenite ore: iron and titanium sulfates. It was found that $X(t)$ dependencies have a form of convex curves up to the acid concentration of $85 \mathrm{wt} \%$ and the curves are well approximated by straight lines from the moment the reaction mixture solidifies. The kinetic curves 
for $90 \%$ and $96 \%$ acid (Figure 5) were S-shaped because the curves were concaved to the abscissa axis. In this case, the rate of conversion of ilmenite concentrate was lower compared with the data for $85 \%$ acid.

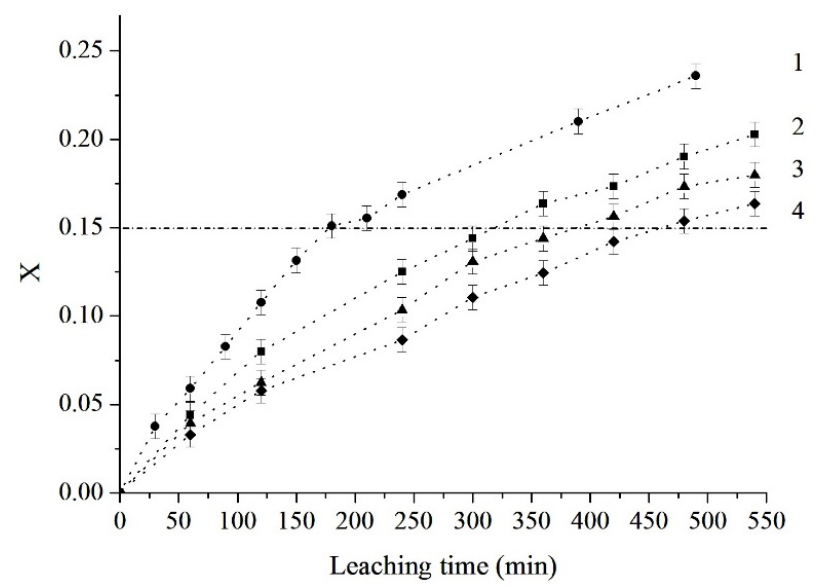

Figure 4. Dependence of the titanium leaching degree on the time of the ground altered ilmenite processing at a temperature of $100{ }^{\circ} \mathrm{C}$ and acid concentrations: $85 \mathrm{wt} \%$ (1), $80 \mathrm{wt} \%$ (2), $60 \mathrm{wt} \%$ (3), and $50 \mathrm{wt} \%$ (4). The dashed line shows the degree of conversion at which the reaction mixture solidifies.

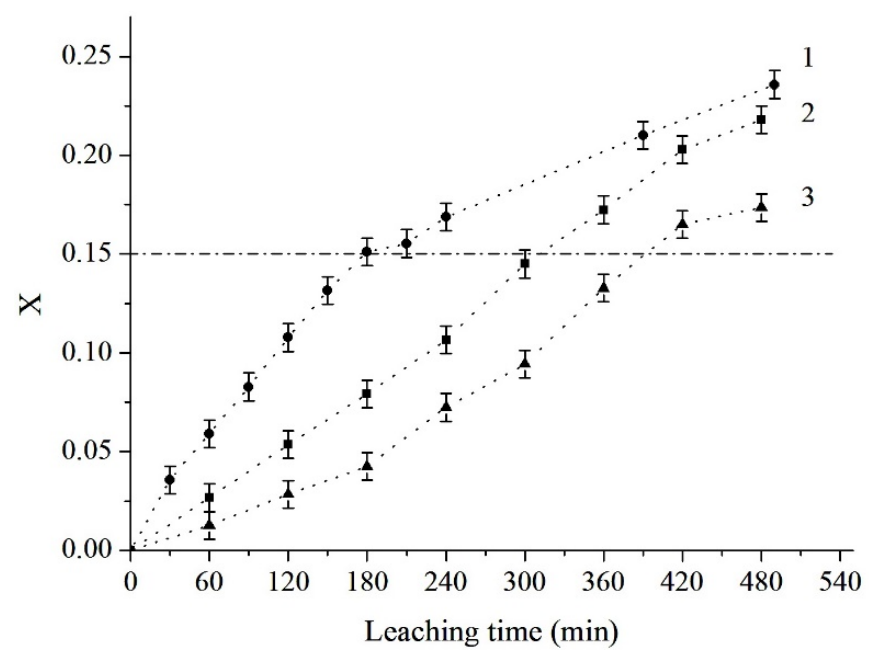

Figure 5. Dependence of the titanium leaching degree on the time of the ground altered ilmenite processing at a temperature of $100{ }^{\circ} \mathrm{C}$ and acid concentrations: $85 \mathrm{wt} \%$ (1), $90 \mathrm{wt} \%$ (2), $96 \mathrm{wt} \%$ (3). The dashed line shows the degree of conversion at which the reaction mixture solidifies.

This S-shaped nature of the change in the degree of conversion during the material processing with concentrated acid can be explained by the decrease in sulfuric acid content and the water content simultaneously increased as reaction (6) proceeds.

$$
\mathrm{Fe}_{2} \mathrm{Ti}_{3} \mathrm{O}_{9}+12 \mathrm{H}^{+}=2 \mathrm{Fe}^{3+}+3 \mathrm{TiO}^{2+}+6 \mathrm{H}_{2} \mathrm{O}
$$

The $X(t)$ curves had a maximum at $\mathrm{C}\left(\mathrm{H}_{2} \mathrm{SO}_{4}\right)=85 \mathrm{wt} \%$. A reduction of the leaching degree was observed by carrying out the process using sulfuric acid with concentrations above 85 wt $\%$ (Figure 6). 


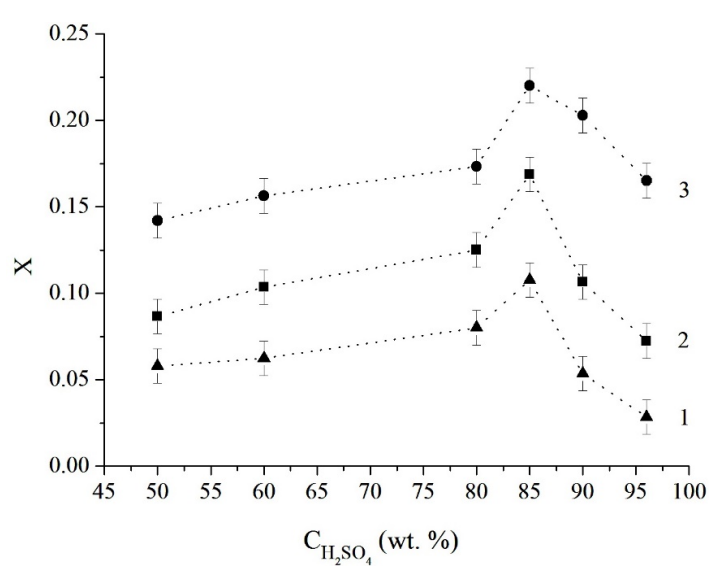

Figure 6. The dependence of the leaching degree of titanium on the concentration of sulfuric acid and the duration of the leaching process $120 \mathrm{~min}$ (1), $240 \mathrm{~min}(2)$, and $420 \mathrm{~min}$ (3).

It is necessary to determine the limiting stage of the process to identify possible ways to optimize it. Various equations were used to describe the heterogeneous reactions to analyze the kinetic data presented above. Statistical processing of the data on the Fisher dispersion relation at a significance level of 0.05 showed that the linearity hypothesis could be accepted for the most known equations, but the values of their correlation coefficients differed significantly. The best results in describing the rate of sulfuric acid decomposition of ilmenite were obtained with the equations of the "contracting sphere" model.

The initial section of the $X(t)$ curve until the sludge formed (Figure 7) is best described by the kinetic equation of the "contracting sphere" model with a limiting stage of the chemical reaction $\left(R^{2}=0.9866\right)$ :

$$
k_{1} t=1-(1-X)^{1 / 3}
$$

The linear sections of the $X(t)$ curves, which are observed after solidification of the reaction mixture, are well described by the external diffusion equation:

$$
X=k_{2} t
$$

where $k_{1}$ is a rate constant for the kinetic equation of a "contracting sphere" model with a limiting stage of a chemical reaction and $k_{2}$ is a rate constant for the equation of external diffusion.

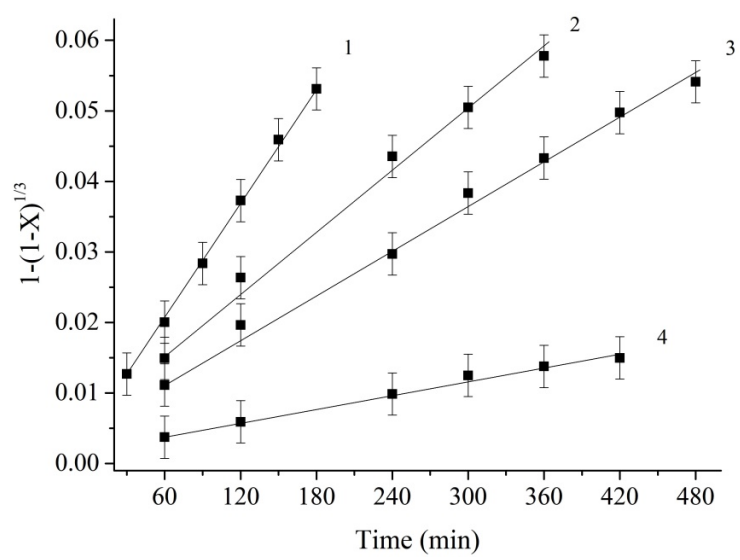

Figure 7. Dependence of the titanium leaching degree on time during the sulfatization of the ground ilmenite concentrate in the coordinates of the equation of the "contracting sphere" model with the limiting stage of the chemical reaction (8), grinding time of $2 \mathrm{~h}$, temperature of $100{ }^{\circ} \mathrm{C}$, and the sulfuric acid concentrations of: $1-85 \mathrm{wt} \% ; 2-80 \mathrm{wt} \% ; 3-60 \mathrm{wt} \%, 4-50 \mathrm{wt} \%$. 
The dissolution rate of ilmenite will increase with a dilution of the acid and the shape of the kinetic curve will change. The rate constants for the titanium extraction from ilmenite concentrate were compared with the concentrations of acid solutions (Figure 7). The rate constants were calculated according to Equation (7) for the initial sections of the kinetic curves in Figures 4 and 5.

It was found that the leaching process should be considered as a two-stage process for the mechanism of the ilmenite processing with sulfuric acid. This leaching process is described by Equations (7) and (8).

The observed rate constant is related to the rate constant of the chemical reaction $\left(k^{*}\right)$ under the condition of the kinetics of the first or pseudo-first order of chemical reaction, according to the "contracting sphere" model:

$$
k=\frac{k^{*} C_{0}}{R_{0} n_{0}}
$$

where $R_{0}$ is the initial particle radius of the solid reagent; $n_{0}$ is a molar density; and $C_{0}$ is the reagent concentration in the core of the liquid phase stream.

The dependence $k\left(C_{0}\right)$ must be linear and the slope of this straight line is proportional to the rate constant of the chemical reaction and inversely proportional to the particle size of the solid reagent, according to this equation. This pattern is well supported by the data in Figure 8 up to the acid concentration of $85 \%$.

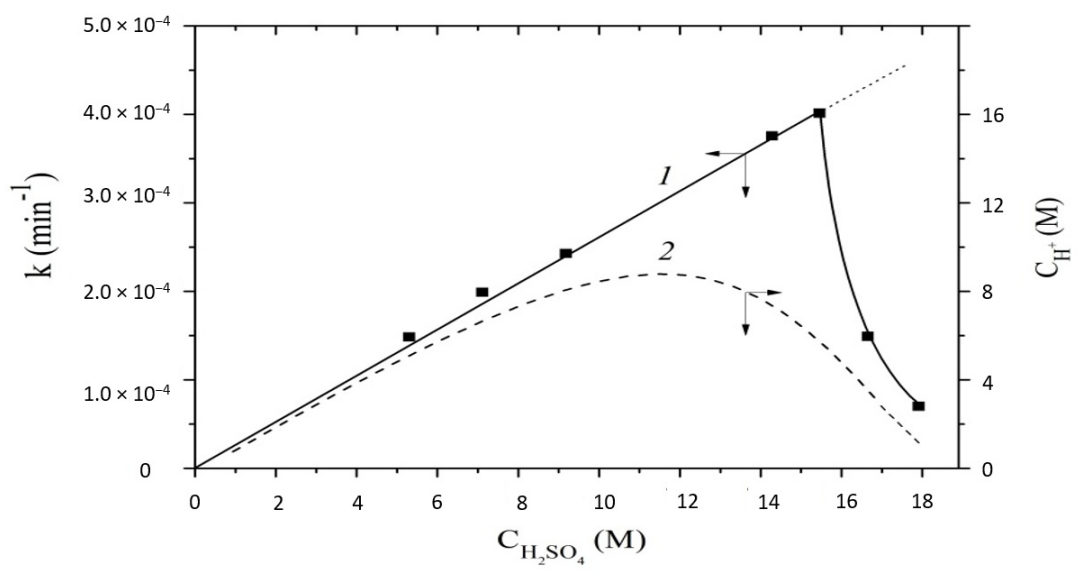

Figure 8. A comparison of the observed constants of ilmenite leaching rate (line 1) with the concentrations of $\mathrm{H}^{+}$in the solutions (line 2).

The rate constant sharply decreased at $C_{0}>85 \%$ and can be explained within the framework of the "contracting sphere" model by a decrease in the solution of sulfuric acid of those particles that are directly involved in the chemical dissolution of ilmenite. The "free" hydrogen ions are considered as such particles. The term "free hydrogen ions" is used for simplification, since one should take into account its hydration and the formation of associates in concentrated solutions, for example, $\mathrm{H}_{3} \mathrm{O}^{+} \cdot \mathrm{HSO}_{4}^{-}$.

It is obvious that $\mathrm{C}\left(\mathrm{H}^{+}\right)<<\mathrm{C}\left(\mathrm{H}_{2} \mathrm{SO}_{4}\right)$ in concentrated solutions of acids and, therefore, hydrogen ions cannot be the main participants in the reaction process. To illustrate this conclusion, based on the data in the literature [29], we calculated the concentration of hydrogen ions depending on the acid content in the solution and the temperature of $100{ }^{\circ} \mathrm{C}$ (Figure 8, curve 2). According to these data, the concentration of hydrogen ions decreased rapidly starting from $12 \mathrm{M}$ solutions, while the efficiency of the leaching process continued to increase up to $C=85 \%$.

To explain the data in Figure 8, it is necessary to take into account that the $85 \mathrm{wt} \%$ concentration of sulfuric acid corresponds to $50 \mathrm{~mol} \%$. This means that the content of acid and water is 1:1. The proportion of $\mathrm{H}_{2} \mathrm{SO}_{4} \cdot \mathrm{H}_{2} \mathrm{O}$ hydrates in the solution was decreased at $\mathrm{C}>50 \mathrm{~mol} \%$, and the proportion of unhydrated $\mathrm{H}_{2} \mathrm{SO}_{4}$ molecules was increased. We have to consider that the electronic properties of particles $\mathrm{H}_{2} \mathrm{SO}_{4} \cdot \mathrm{H}_{2} \mathrm{O}$ and $\mathrm{H}_{2} \mathrm{SO}_{4}$ are different and governed by different mechanisms. 
Therefore, the observed rate constants should be compared, not with the concentration of sulfuric acid, but with the concentration of its hydrated forms. As is widely known, sulfuric acid forms five hydrates of $\mathrm{H}_{2} \mathrm{SO}_{4} \cdot n \mathrm{H}_{2} \mathrm{O}$, where $n=1,2,3,4$ and 6.5. If we summarize its content in the solution and compare its sum with the concentration of the sulfuric acid solution, we can obtain a graph of the change in the content of sulfuric acid hydrates with a maximum at a solution concentration at $50 \mathrm{~mol} \%$ (Figure 9).

The rate of the leaching correlated well with the content of $\mathrm{H}_{2} \mathrm{SO}_{4} \cdot n \mathrm{H}_{2} \mathrm{O}$ particles in the solution both in the linear section (where $k$ is directly proportional to $C_{0}$ ) and in the decaying section at $C_{0}>50 \mathrm{~mol} \%$, as can be seen from the comparison of Figures 8 and 9 .

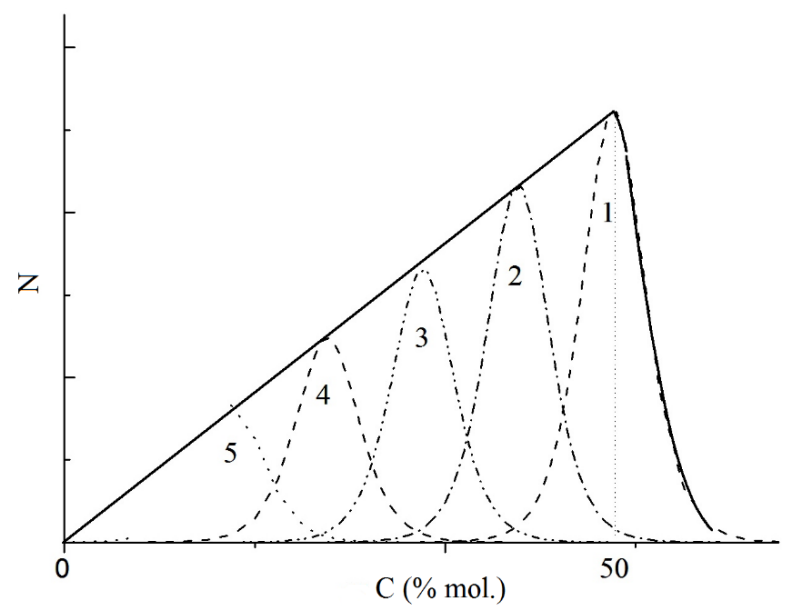

Figure 9. Schematic representation of the content of $\mathrm{H}_{2} \mathrm{SO}_{4} \cdot \mathrm{H}_{2} \mathrm{O}$ hydrates (curves 1-5 for $n=1,2,3,4$, and 6.5) and its sum (solid line) depending on the concentration of sulfuric acid.

To confirm the hypothesis about the difference in the properties of $\mathrm{H}_{2} \mathrm{SO}_{4} \cdot n \mathrm{H}_{2} \mathrm{O}$ and $\mathrm{H}_{2} \mathrm{SO}_{4}$, we performed the quantum chemical calculations using the Gaussian 09W software package. The calculations were made in the framework of density functional theory using the B3LYP functional and basic sets of atomic functions $6-31+\mathrm{G}(\mathrm{d}, \mathrm{p})[69,70]$. As calculations showed, the hydrates $\mathrm{H}_{2} \mathrm{SO}_{4} \cdot \mathrm{H}_{2} \mathrm{O}$ and $\mathrm{H}_{2} \mathrm{SO}_{4} \cdot 2 \mathrm{H}_{2} \mathrm{O}$ can be represented in the form of coordination compounds $\left[\mathrm{SO}(\mathrm{OH})_{4}\right]^{0}$ and $\left[\mathrm{S}(\mathrm{OH})_{6}\right]^{0}$, where sulfur atoms are surrounded by five and six oxygen atoms, respectively. The stability of such structures allows us to suggest the possibility of the coordination of a sulfuric acid molecule on the oxide surface of mineral raw materials through a sulfur atom (its effective charge is +2.545 ) with the formation of coordination bonds of the form $\mathrm{O}^{2-}$...S(VI) with the participation of vacant d-orbitals of the sulfur atom. Two methods of coordination on the surface of the solid reagent are more probable for sulfuric acid hydrates when the coordination sphere of the sulfur atom is saturated: (i) with the formation of a hydrogen bond between the oxygen atoms on the surface of the oxide mineral and the hydrogen atoms in $\mathrm{H}_{2} \mathrm{SO}_{4} \cdot n \mathrm{H}_{2} \mathrm{O}$ particles and (or) (ii) with the formation of coordination bonds between metal cations on the surface of the oxide mineral and oxygen atoms in $\mathrm{H}_{2} \mathrm{SO}_{4} \cdot n \mathrm{H}_{2} \mathrm{O}$ particles. According to the theory of the transition state, a change in the structure of the activated complex during a chemical transformation will necessarily affect its direction and speed. Therefore, the different coordination of the molecules of sulfuric acid and its hydrates on the surface of the oxide mineral well explains the experimentally observed fact of a decrease in the rate of chemical decomposition of ilmenite in highly concentrated solutions of sulfuric acid.

\subsection{Chemical Activation of the Raw Material via NaF Addition}

In addition to the concentration of sulfuric acid, within the framework of the idea of the chemical activation of the process, we also considered the effect of fluoride ions on the efficiency of acid leaching.

A fluoride leaching method is one of the alternative and prospective methods for the processing of titanium-bearing materials. It seems interesting to research the effect of the addition of fluoride ions into the reaction mixture. As is known, the fluorides can actively interact with iron and titanium 
oxides. Sodium fluoride was utilized as a fluoride precursor. The process was carried out in a Teflon reactor with a hermetically sealed lid to reduce the loss of fluoride ions due to the evaporation of hydrogen fluoride. The experiments showed a regular increase in the rate of leaching with an increase in the content of fluoride ions. The results of the kinetic studies are presented in Figure 10.

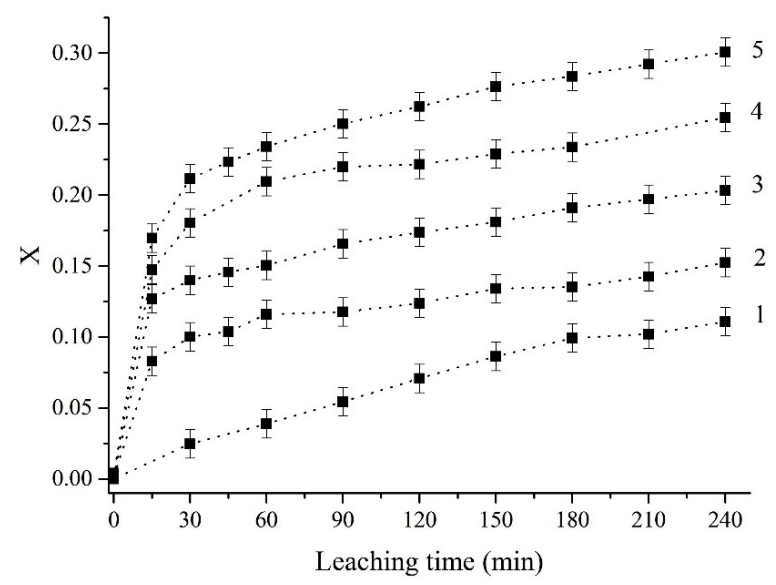

Figure 10. Dependence of the extraction degree on the time of the ilmenite leaching in $85 \mathrm{wt} \%$ sulfuric acid at a temperature of $100{ }^{\circ} \mathrm{C}$. The mass ratio of ilmenite concentrate to NaF: 1:0 (1); 1:0.25 (2); 1:0.5 (3); 1:0.75 (4); $1: 1(5)$.

At the beginning of the leaching process, all curves retained the shape of convex curves and after that, the data became linear. An increase in the weight of a sample of sodium fluoride led to a regular increase in the titanium extraction degree into solution, as shown in Figure 10. It was found that the addition of sodium fluoride to the ilmenite sample in the mass ratio of 1:1 increased the degree of titanium extraction by almost six times after $60 \mathrm{~min}$ of leaching.

The photography of the sludge obtained during the leaching by the sulfate-fluoride method is presented in Figure 11. The sludge contained components of ilmenite concentrate that did not dissolve in sulfuric acid during the leaching process. Holes and recesses were visible on the sample surface and can be explained by the formation of gaseous HF bubbles. The speed of the process at the interface between such bubbles and ilmenite particles can be controlled by both the reaction rate and the rate of reagent diffusion into the reaction zone.

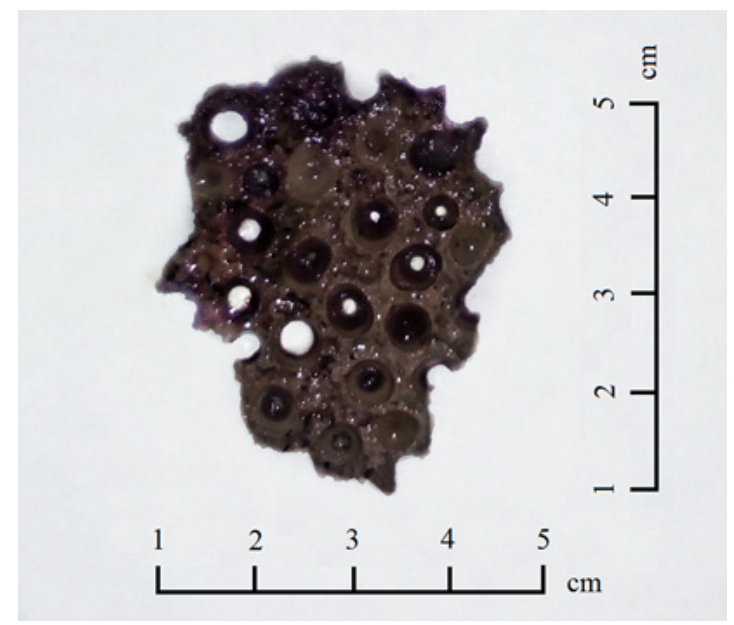

Figure 11. The sample of altered ilmenite after the leaching process in the presence of sodium fluoride. 


\subsection{Influence of Temperature on the Leaching Process}

The results of our kinetic study in the temperature range of $100-200^{\circ} \mathrm{C}$ are presented in Figures 12 and 13. The experiments were carried out in the isothermal conditions with a mass ratio of ilmenite:sulfuric acid $=1: 2$ and at the initial concentration of sulfuric acid solutions of $85 \mathrm{wt} \%$.

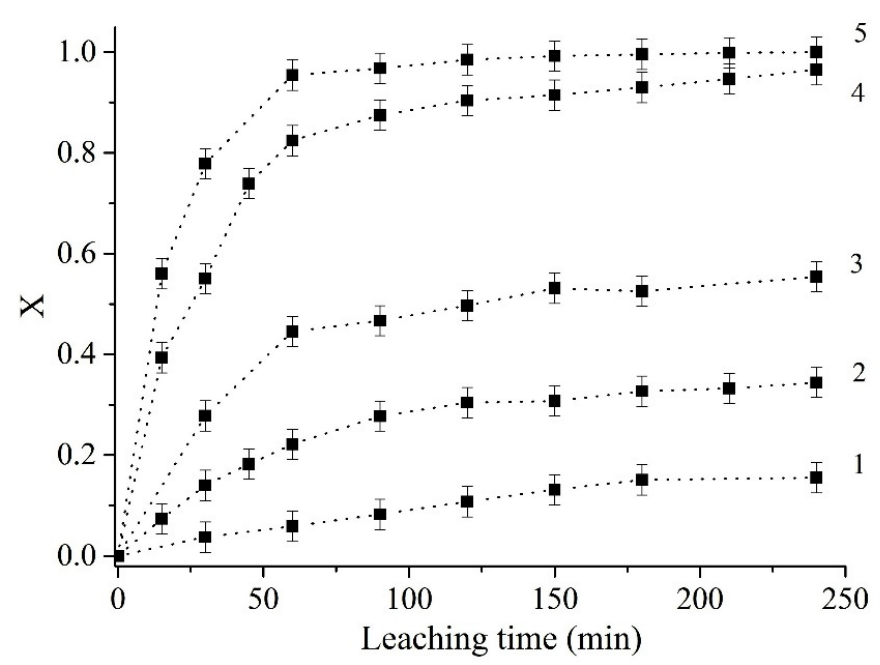

Figure 12. The kinetics of the leaching of ilmenite concentrate during processing in $\mathrm{H}_{2} \mathrm{SO}_{4}(85 \mathrm{wt} \%)$ at temperatures of $100{ }^{\circ} \mathrm{C}(1), 120^{\circ} \mathrm{C}(2), 140{ }^{\circ} \mathrm{C}(3), 160{ }^{\circ} \mathrm{C}(4)$, and $180{ }^{\circ} \mathrm{C}$ (5).

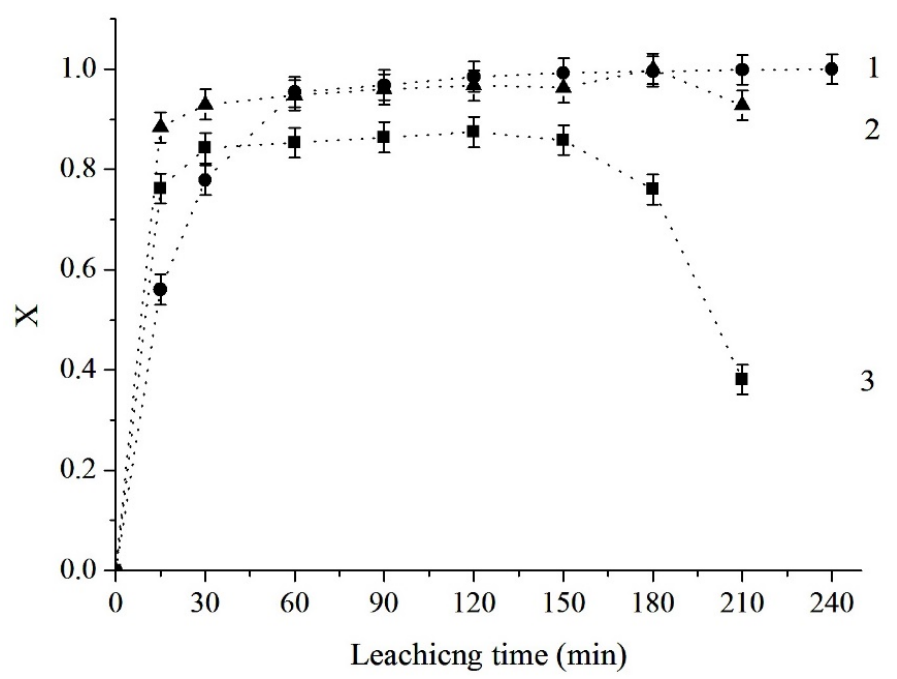

Figure 13. The kinetics of the leaching of ilmenite concentrate during processing in $\mathrm{H}_{2} \mathrm{SO}_{4}(85 \mathrm{wt} \%)$ at temperatures of $180^{\circ} \mathrm{C}(1) 190{ }^{\circ} \mathrm{C}(2)$ and $200{ }^{\circ} \mathrm{C}$ (3).

The titanium leaching degree was calculated as the ratio of the amount of titanium transferred to the solution to its content in ilmenite concentrate in the form of pseudorutile, pseudobrookite, and ilmenite. Titanium dioxide in rutile form (23.5 wt \%, Figure 3$)$ was considered as a ballast substance due to its insolubility in sulfuric acid and, therefore, was not taken into account in the calculations.

It was found that all of the investigated dependences $X(t)$ had the form of convex curves on the initial sections and these curves were well approximated by straight lines since the moment of solidification of the reaction mixture. A decrease in the degree of titanium extraction was observed on the $X(t)$ plots for 190 and $200{ }^{\circ} \mathrm{C}$ after 150 and $120 \mathrm{~min}$ (Figure 13).

There was a similar effect for non-altered ilmenites, where the main component of $\mathrm{FeTiO}_{3}$ was also described $[14,17,71]$. Obviously, the reason for the decrease in the degree of titanium extraction at $200{ }^{\circ} \mathrm{C}$ was not due to some individual chemical properties of the pseudorutile $\left(\mathrm{Fe}_{2} \mathrm{Ti}_{3} \mathrm{O}_{9}\right)$, but the 
properties of the final product (titanium sulfate salts) of the researched process. According to the well-known data on the solubility of titanium(IV) sulfate salts [61], the dominant form is the Ti( $\left(\mathrm{SO}_{4}\right)_{2}$ salt at $200{ }^{\circ} \mathrm{C}$ in $85 \%$ acid. This salt, among all known titanium sulfate salts, is soluble in both water and dilute acid solutions. Such increased solubility is well explained by the rapid conversion in the water presence of the $\mathrm{Ti}(\mathrm{IV})$ cation to the titanyl cation $\mathrm{TiO}^{2+}$. Therefore, it is obvious that the formation of $\mathrm{Ti}\left(\mathrm{SO}_{4}\right)_{2}$ does not explain the decrease in the titanium content in the solution during sulfuric acid leaching of the ilmenite concentrate. The problem can be solved by the concentration of sulfuric acid where the latter is continuously reduced due to its consumption in the reaction and the release of water during the reaction between pseudorutile and sulfuric acid.

According to the solubility polytherm of the $\mathrm{TiO}_{2}-\mathrm{SO}_{3}-\mathrm{H}_{2} \mathrm{O}$ system, the anhydrous $\mathrm{TiOSO}_{4}$ salt becomes the dominant form under equilibrium conditions with a decrease in the acid concentration during the leaching [61]. This salt is insoluble not only in concentrated sulfuric acid, but also in its diluted solutions. Thus, the sequential formation of two salts of $\mathrm{Ti}\left(\mathrm{SO}_{4}\right)_{2}$ and $\mathrm{TiOSO}_{4}$ is possible in the leaching process at $200{ }^{\circ} \mathrm{C}$ [72]. These salts can precipitate as the titanium content in the solution increases.

Ti(IV) ions belong to the group of cations with a low degree of lability according to the chemistry of coordination compounds. It is believed that the large positive charge of the titanium cation and its relatively small radius increases the activation energy of the substitution reaction, which reduces the rate of exchange of intra-sphere ligands to other ligands from the external environment of the solution. It can be assumed that the ligand exchange rate in the coordination sphere of $\mathrm{Ti}(\mathrm{IV})$ ions noticeably increases with an increase in the temperature of more than $190^{\circ} \mathrm{C}$. This contributes to the transition of the $\mathrm{Ti}(\mathrm{IV})-\mathrm{H}_{2} \mathrm{O}-\mathrm{H}_{2} \mathrm{SO}_{4}$ system from a metastable to a true equilibrium state with the formation of the low-soluble polynuclear sulfate complexes of titanium. Thus, the observed effect of a decrease in the titanium extraction degree at $200{ }^{\circ} \mathrm{C}$ can be well explained by the polymerization of $\mathrm{TiO}^{2+}$ ions with the participation of bridging $\mathrm{SO}_{4}$-bonds. The temperature range for the existence of the $\mathrm{TiOSO}_{4}$ salt extends to $140{ }^{\circ} \mathrm{C}$, according to the solubility polytherm of the $\mathrm{TiO}_{2}-\mathrm{SO}_{3}-\mathrm{H}_{2} \mathrm{O}$ system and therefore it is not clear why the irreversible polymerization of $\mathrm{TiOSO}_{4}$ is not observed at temperatures below $200{ }^{\circ} \mathrm{C}$. A possible explanation for this effect is that the polymerization proceeds relatively slowly and the insoluble form of $\mathrm{TiOSO}_{4}$ does not have time to form in noticeable amounts in $30 \mathrm{~min}$.

In addition, the effect of temperature on the titanium leaching process from rutile with the addition of sodium fluoride into the sulfuric acid solution was studied. The experiments were performed under isothermal conditions in the temperature range from 70 to $165^{\circ} \mathrm{C}$, and with the molar ratio of Ti: $\mathrm{F}=1: 2$ and $\mathrm{H}_{2} \mathrm{SO}_{4}$ concentration of $85 \mathrm{wt} \%$ (Figure 14).

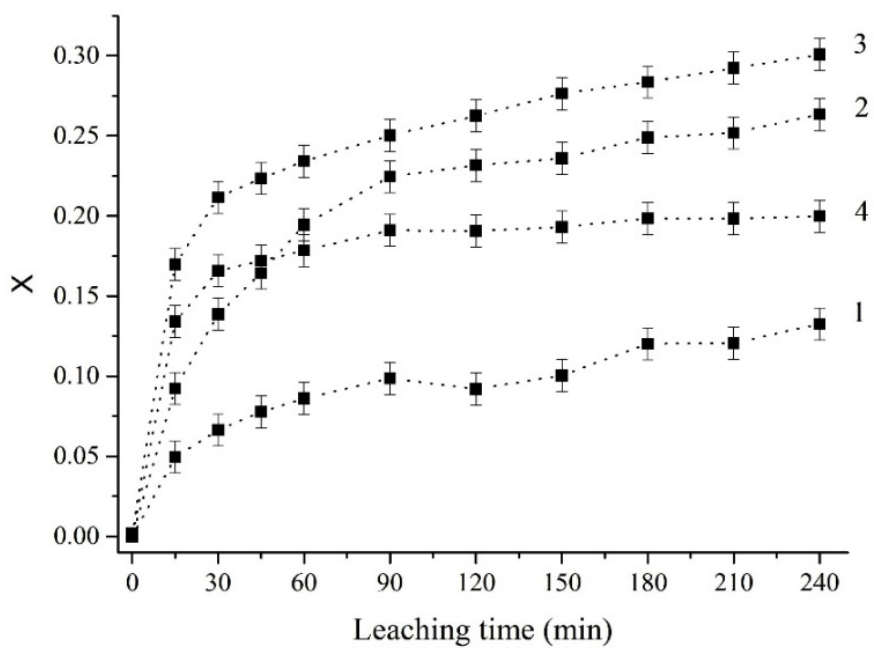

Figure 14. The kinetics of the leaching of ilmenite concentrate during processing in $\mathrm{H}_{2} \mathrm{SO}_{4}(85 \mathrm{wt} \%)$ and mass ratio Ti: $\mathrm{F}=1: 1$ at temperatures of $70{ }^{\circ} \mathrm{C}(1), 85^{\circ} \mathrm{C}(2), 100{ }^{\circ} \mathrm{C}(3), 165^{\circ} \mathrm{C}(4)$. 
As can be seen from Figure 14, the highest titanium leaching degree with increasing temperature was achieved during the leaching process at $100{ }^{\circ} \mathrm{C}$. The low titanium degree into the solution at $165^{\circ} \mathrm{C}$ can be explained by the fact that in the acidic environment, the fluoride ions are preferably bound to $\mathrm{HF}$ molecules and consequently quickly evaporate from the reaction mixture. As is known, an azeotropic mixture with a HF concentration of $37.5 \%$ and a boiling point of $109{ }^{\circ} \mathrm{C}$ is formed at the heating of $\mathrm{HF}$ solutions. Therefore, increasing the temperature above $100{ }^{\circ} \mathrm{C}$ intensifies the evaporation process of HF. This leads to the decrease in the fluoride ion concentration in the reaction mixture.

\subsection{Determination of the Activation Energy of the Leaching Process}

The rate constants $k_{1}$ and $k_{2}$ were calculated using Equations (7) and (8) and the data in Figures 12 and 14. The calculation results are shown in Figure 15 in the coordinates of the Arrhenius equation.

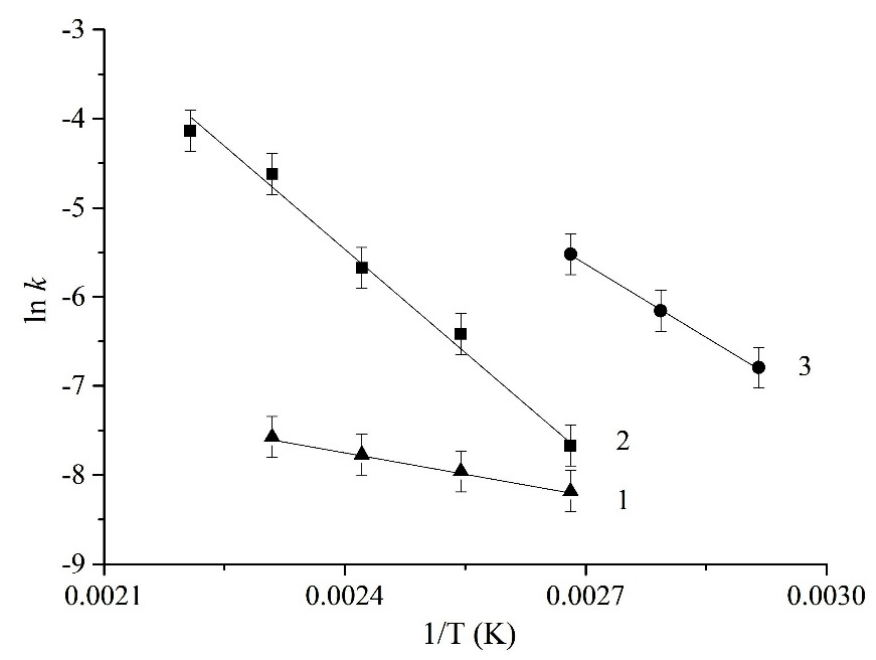

Figure 15. Dependence of the rate constants of the leaching process of altered ilmenite on the temperature in the coordinates of the Arrhenius equation: (1) before the reaction mixture was solidified; (2) after solidification of the reaction mixture; (3) leaching at the NaF presence (the mass ratio of ilmenite to $\mathrm{NaF}$ is $1: 1)$.

The activation energies were calculated on the slope of the obtained linear dependences $\operatorname{lnk}(1 / \mathrm{T})$ (in $\mathrm{kJ} / \mathrm{mol}$ ): 62.8 for the first stage of the leaching process of altered ilmenite, 13.3 for the second stage, and 45.2 for the leaching process of altered ilmenite with the addition of NaF. The influence of fluorides in the second stage of the leaching process was not investigated because the solidification of the reaction mixture with the addition of fluorides did not occur under the experimental conditions.

Thus, the intensification of the leaching of the altered ilmenite is possible in the case of a short grinding of ore raw materials, maintaining the concentration of sulfuric acid not higher than $85 \mathrm{wt} \%$, adding fluorides to the leaching reactor, and carrying out the process at the temperature not higher than $190^{\circ} \mathrm{C}$.

\section{Conclusions}

It was first experimentally proven that the phase composition of ilmenite concentrate changed qualitatively and quantitatively during the grinding process. The quantitative x-ray phase analysis showed the content of ilmenite $(5.3 \%)$, rutile $(4.5 \%)$, and pseudorutile $(90.2 \%)$ in the test sample of ilmenite concentrate before grinding. The content of ilmenite and pseudorutile was decreased to 3.1 and $63.1 \%$, respectively, while the content of rutile increased to $28.7 \%$ and the phase of pseudobrukite appeared in the amount of 5.1\% after grinding for $2 \mathrm{~h}$. It was found that the modification of raw material by sulfuric acid led to the increase in the decomposition rate, and at the same time, a decrease when the ore was utilized due to an increase in the insoluble $\mathrm{TiO}_{2}$ content. 
For the first time, it was shown for the altered ilmenite that the use of sulfuric acid solutions with a concentration of more than $85 \mathrm{wt} \%$ leads to a sharp decrease in the rate constant of the process of the sulfuric acid leaching of titanium. A linear dependence was found between the observed constants of the rate of chemical dissolution of the mineral raw materials and the concentrations of sulfuric acid solutions up to a concentration of $85 \mathrm{wt} \%$. The rate constant decreases sharply with a further increase in the acid concentration, which can be explained by a decrease in the content of particles in the sulfuric acid solution that are directly involved in the chemical dissolution of ilmenite in the framework of the "contracting sphere" model. The optimal acid concentration for the leaching process is $85 \mathrm{wt} \%$. It was suggested that such a reagent in sulfuric acid solutions should be considered not only for $\mathrm{H}_{2} \mathrm{SO}_{4}$ molecules, but its hydrates $\mathrm{H}_{2} \mathrm{SO}_{4} \cdot n \mathrm{H}_{2} \mathrm{O}$, which form activated complexes with a different structure on the surface of the dissolved minerals when compared with the sulfuric acid molecules.

The possibility of intensifying the leaching process of the altered ilmenite due to the addition of fluorides is first described. This possibility opens up the prospects for increasing the efficiency of processing altered ilmenite by the hydrometallurgical method. The addition of sodium fluoride to the ilmenite sample, for example, in a mass ratio of 1:1 increased the degree of titanium extraction by almost six times in 60 min of leaching.

The $X(t)$ dependences on the initial sections had the form of convex curves, and the curves were well approximated by straight lines from the moment the reaction mixture solidified. A kinetic study of the altered ilmenite leaching in the temperature range of $100-200{ }^{\circ} \mathrm{C}$ was carried out. It was first shown that the efficiency of the titanium extraction in the acid leaching process of the altered ilmenite was decreased at a temperature above $190{ }^{\circ} \mathrm{C}$. The titanium losses approached $60 \%$ after $180 \mathrm{~min}$ of acid processing at $200^{\circ} \mathrm{C}$. The observed regularities can be well explained by the formation of the $\mathrm{TiOSO}_{4}$ polymer that is insoluble in acids.

The "contracting sphere" model is well suited for the modeling of the sulfuric acid leaching of the altered ilmenite. The acid processing of the ilmenite concentrate should be considered as a two-stage process as was proven. The activation energies were $62.5 \mathrm{~kJ} / \mathrm{mol}$ per titanium at the first stage of the process and $13.5 \mathrm{~kJ} / \mathrm{mol}$ per titanium at the second stage of the sulfuric acid leaching of the altered ilmenite. The addition of $\mathrm{NaF}$ into the reaction mixture made it possible to reduce the activation energy to $45 \mathrm{~kJ} / \mathrm{mol}$, which allowed us to consider sodium fluoride as an activator of the ore raw materials in sulfuric acid leaching.

The optimal conditions of the altered ilmenite leaching were also determined. The concentration of sulfuric acid has to be not higher than $85 \mathrm{wt} \%$, the process temperature has to be less than $190{ }^{\circ} \mathrm{C}$, and the addition of sodium fluoride to the reaction mixture in a mass ratio has to be Ti: $\mathrm{F}=1: 1$.

Author Contributions: Conceptualization, A.V.D. and M.V.N.; Methodology, M.V.N.; Software, A.V.D.; Validation, M.V.N.; Investigation, A.V.D. and M.V.N.; Resources, M.V.N.; Writing—original draft preparation, A.V.D. and M.V.N.; Writing-review and editing, A.K. and B.L.; Visualization, A.V.D.; Supervision, B.L.; Project administration, A.K.; Funding acquisition, B.L. All authors have read and agreed to the published version of the manuscript.

Funding: The work was supported by R\&D project $24 / 170290$ of the Ukrainian State University of Chemical Technology.

Acknowledgments: A.V.D. and M.V.N. are grateful to Alexander Pasenko for the provided samples of altered ilmenite, as well as to Yuri Kalashnikov for helping with developing a method for studying the leaching kinetics. A.K. and B.L. acknowledge financial support from the Slovenian Research Agency (research core funding No. P2-0152).

Conflicts of Interest: The authors declare no conflicts of interest.

\section{References}

1. Haverkamp, R.G.; Kruger, D.; Rajashekar, R. The digestion of New Zealand ilmenite by hydrochloric acid. Hydrometallurgy 2016, 163, 198-203. [CrossRef]

2. Mahmoud, H.H.; Afifi, A.A.I.; Ibrahim, I.A. Reductive leaching of ilmenite ore in hydrochloric acid for preparation of syntetic rutile. Hydrometallurgy 2004, 73, 99-109. [CrossRef] 
3. Mostafa, N.Y.; Mahmoud, M.H.H.; Heiba, Z.K. Hydrolysis of $\mathrm{TiOCl}_{2}$ leached and purified from low-grade ilmenite mineral. Hydrometallurgy 2013, 139, 88-94. [CrossRef]

4. Han, J.; Zhang, J.; Feng, W.; Chen, X.; Zhang, L.; Tu, G. A clean process to prepare high-quality acid-soluble titanium slag from titanium middling ore. Minerals 2019, 9, 460. [CrossRef]

5. Karelin, V.A.; Kameneva, O.V. Ftoridnyiy metod pererabotki rutilovogo kontsentrata [Fluoride processing method of rutile concentrate]. Izvestiya Tomskogo politehnicheskogo universiteta 2006, 309, 94-99. (In Russian)

6. Gordienko, P.; Yarusova, S.; Pashnina, E.; Zhevtun, I. Hydrofluoride method of complex processing of titanium-containing raw materials. Process Eng. J. 2017, 1, 30-33. [CrossRef]

7. Gordienko, P.; Scheka, S.; Bakeeva, N.; Pashnina, E. Gidroftoridnyiy metod pererabotki ilmenitovyih kontsentratov [Hydrofluoride method for processing ilmenite concentrates]. Min. Inf. Anal. Bull. (Sci. Tech. J.) 2010, 4, 278-288. (In Russian)

8. Olanipekun, E. A kinetic study of the leaching of a Nigerian ilmenite ore by hydrochloric acid. Hydrometallurgy 1999, 53, 1-10. [CrossRef]

9. Rahman, S.; Rahman, T.P.; Nugraha, I.; Nugroho, D.W. Optimization $\mathrm{H}_{2} \mathrm{SO}_{4}$ Concentration on the Leaching Process of Extracting Titanium from Zircon Sand. In Proceedings Book of ICETSR-Malaysia Handbook on the Emerging Trends in Scientific Research; PAK Publishing Group: Singapore, 2014; pp. 791-794.

10. Wang, X.; Li, C.; Yue, H.; Yuan, S.; Liu, C.; Tang, S.; Liang, B. Effects of mechanical activation on the digestion of ilmenite in dilute $\mathrm{H}_{2} \mathrm{SO}_{4}$. Chin. J. Chem. Eng. 2019, 27, 575-586. [CrossRef]

11. Zhang, W.; Zhu, Z.; Cheng, C.Y. A literature review of titanium metallurgical processes. Hydrometallurgy 2011, 108, 177-188. [CrossRef]

12. Gázquez, M.J.; Bolívar, J.P.; Garcia-Tenorio, R.; Vaca, F. A review of the production cycle of titanium dioxide pigment. Mater. Sci. Appl. 2014, 5, 441-458. [CrossRef]

13. Amer, A.M. Alkaline pressure leaching of mechanically activated Rosetta ilmenite concentrate. Hydrometallurgy 2002, 167, 125-133. [CrossRef]

14. Urakaev, F.K. Influence of the conditions of mechanical activation of the mixture of ilmenite and carbon on the pigment preparation. Int. J. Miner. Process. 2011, 101, 37-41. [CrossRef]

15. Chen, Y.; Williams, J.S.; Campbell, S.J.; Wang, G.M. Increased dissolution of ilmenite induced by high-energy ball milling. Mater. Sci. Eng. 1999, 271, 485-490. [CrossRef]

16. Yarkadas, G.; Toplan, H.; Yildiz, K. Effect of mechanical activation and iron powder addition on acidic leaching of pseudorutile. SAÜ Fen Bilimleri Dergis 2009, 13, 18-21.

17. Li, C.; Liang, B.; Chen, S.P. Combined milling-dissolution of Panzhihua ilmenite in sulfuric acid. Hydrometallurgy 2006, 82, 93-99. [CrossRef]

18. Fu, X.; Wang, Y.; Wei, F. Phase Transitions and Reaction Mechanism of Ilmenite Oxidation. Metall. Mater. Trans. 2010, 41, 1338-1348. [CrossRef]

19. Sasikumar, C.; Rao, D.S.; Srikanth, S.; Srikanth, N.K.; Mehrotra, S.P. Dissolution studies of mechanically activated Manavalakurichi ilmenite with $\mathrm{HCl}$ and $\mathrm{H}_{2} \mathrm{SO}_{4}$. Hydrometallurgy 2007, 88, 154-169. [CrossRef]

20. Kostova, N.G.; Achimovičová, M.; Eliyas, A.; Velinov, N. $\mathrm{TiO}_{2}$ obtained from mechanically activated ilmenite and its photocatalytic properties. Bulg. Chem. Commun. 2015, 47, 317-322.

21. Sasikumar, C.; Rao, D.S.; Srikanth, S.; Ravikumar, B.; Mukhopadhyay, N.K.; Mehrotra, S.P. Effect of mechanical activation on the kinetics of sulfuric acid leaching of beach sand ilmenite from Orissa, India. Hydrometallurgy 2004, 75, 189-204. [CrossRef]

22. Welham, N.J.; Llewellyng, D.J. Mechanical enhancement of the dissolution of ilmenite. Miner. Eng. 1998, 11, 827-841. [CrossRef]

23. Picazo-Rodríguez, N.G.; Soria-Aguilar, M.; Martínez-Luévanos, A.; Almaguer-Guzmán, I.; Chaidez-Félix, J.; Carrillo-Pedroza, F.R. Direct acid leaching of sphalerite: An approach comparative and kinetics analysis. Minerals 2020, 10, 359. [CrossRef]

24. Qin, S.C.; Jiang, K.X.; Wang, H.B.; Zhang, B.S.; Wang, Y.F.; Zhang, X.D. Research on Behavior of Iron in the Zinc Sulfide Pressure Leaching Process. Minerals 2020, 10, 224. [CrossRef]

25. Castillo, J.; Sepúlveda, R.; Araya, G.; Guzmán, D.; Toro, N.; Pérez, K.; Rodríguez, M.; Navarra, A. Leaching of white metal in a NaCl- $\mathrm{H}_{2} \mathrm{SO}_{4}$ system under environmental conditions. Minerals 2019, 9, 319. [CrossRef]

26. Toro, N.; Saldaña, M.; Castillo, J.; Higuera, F.; Acosta, R. Leaching of manganese from marine nodules at room temperature with the use of sulfuric acid and the addition of tailings. Minerals 2019, 9, 289. [CrossRef] 
27. Han, K.N.; Rubcumintara, T.; Fuerstenau, C. Leaching behavior of ilmenite with sulfuric acid. Metall. Trans. B 1987, 6, 325-330. [CrossRef]

28. Lasheen, T.A. Sulfate digestion process for high purity $\mathrm{TiO}_{2}$ from titania slag. Front. Chem. Eng. China 2009, 3, 155-160. [CrossRef]

29. Young, T.F.; Blatz, L.A. The variation of the properties of electrolytic solutions with degrees of dissociation. Chem. Rev. 1949, 44, 93-115. [CrossRef]

30. Xiong, X.; Wang, Z.; Wu, F.; $\mathrm{Li}, \mathrm{X} . ; \mathrm{Guo}, \mathrm{H}$. Preparation of $\mathrm{TiO}_{2}$ from ilmenite using sulfuric acid decomposition of the titania residue combined with separation of $\mathrm{Fe}^{3+}$ with EDTA during hydrolysis. Adv. Powder Technol. 2013, 24, 60-67. [CrossRef]

31. Baba, A.A.; Swaroopa, S.; Ghosh, M.K.; Adekola, F.A. Mineralogical characterization and leaching behavior of Nigerian ilmenite ore. Trans. Nonferrous Met. Soc. China 2013, 23, 2743-2750. [CrossRef]

32. Razavi, R.; Hosseini, S.M.A.; Ranjbar, M. Production of nanosized synthetic Rutile from ilmenite concentrate by sonochemical $\mathrm{HCl}$ and $\mathrm{H}_{2} \mathrm{SO}_{4}$ leaching. Iran. J. Chem. Chem. Eng. 2014, 33, 29-36.

33. Jia, L.; Liang, B.; Lü, L.; Yuan, S.; Zheng, L.; Wang, X.; Li, C. Beneficiation of titania by sulfuric acid pressure leaching of Panzhihua ilmenite. Hydrometallurgy 2014, 150, 92-98. [CrossRef]

34. Nayl, A.A.; Aly, H.F. Acid leaching of ilmenite decomposed by KOH Part 1. Hydrometallurgy 2009, 97, 86-93. [CrossRef]

35. Nayl, A.A.; Awwad, N.S.; Aly, H.F. Kinetics of acid leaching of ilmenite decomposed by KOH. Part 2. Leaching by $\mathrm{H}_{2} \mathrm{SO}_{4}$ and $\mathrm{C}_{2} \mathrm{H}_{2} \mathrm{O}_{4}$. Hydrometallurgy 2009, 168, 793-799. [CrossRef]

36. Liu, Y.; Qi, T.; Chu, J.; Qijie, T.; Zhang, Y. Decomposition of ilmenite by concentrated KOH solution under atmospheric pressure. Int. J. Miner. Process 2006, 81, 79-84. [CrossRef]

37. Jabłonski, M.; Przepiera, A. Hazard in reaction of titanium raw materials with sulphuric acid. J. Therm. Anal. Calorim. 2006, 83, 571-573. [CrossRef]

38. Jabłonski, M.; Tylutka, S. The influence of initial concentration of sulfuric acid on the degree of leaching of the main elements of ilmenite raw materials. J. Therm. Anal. Calorim. 2015, 124, 355-361. [CrossRef]

39. Wahyuningsih, S.; Ramelan, A.H.; Munifa, R.M.I.; Saputri, L.N.M.Z.; Chasanah, U. Synthesis of $\mathrm{TiO}_{2}$ nanorods from titania and titanyl sulfate produced from ilmenite dissolution by hydrothermal method. J. Phys. Conf. Ser. 2016, 776, 1-6. [CrossRef]

40. Rakov, E.G. Chemistry and Technology of Inorganic Fluorides; D.I. Mendeleyev MCTI Press: Moscow, Russia, 1990; p. 162.

41. Parfenov, O.G.; Pashkov, G.L. Problemy Sovremennoi Metallurgii Titana [Problems of Modern Metallurgy of Titanium]; Sib. Otd. Ross. Akad. Nauk: Novosibirsk, Russia, 2008; p. 279. (In Russian)

42. Sarfo, P.; Frasz, T.; Das, A.; Young, C. Hydrometallurgical recovery and process optimization of rare earth fluorides from recycled magnets. Minerals 2020, 10, 340. [CrossRef]

43. Opalovsky, A.A.; Labkov, E.U.; Torosyan, S.S.; Dzhambek, A.A. DTA study of the reactions of non-metal fluorides with inorganic compounds. J. Therm. Anal. Calorim. 1979, 15, 67-77. [CrossRef]

44. Melnichenko, E.I.; Epov, D.G.; Scheka, S.A.; Krysenko, G.F. Sposob Pererabotki Titansoderzhashchego Mineral'Nogo Syr'ya [A Method of Processing Titanium-Containing Mineral Raw Materials]. Russia Patent 2136771, 10 September 1999.

45. Karelin, V.A.; Karelin, A.I. Ftoridnaya Tehnologiya Pererabotki Kontsentratov Redkih Metallov [Fluoride Technology for Processing Rare Metal Concentrates]; Izd-vo NTL: Tomsk, Russia, 2004; p. 184. (In Russian)

46. Swedsen, S.S. Treatment of Titanium-Bearing Materials. U.S. Patent 2042435, C1 23-202, 26 May 1934.

47. Solovov, V.A.; Nikolenko, N.V.; Kovalenko, V.L.; Kotok, V.A.; Burkov, A.A.; Kondrat'ev, D.A.; Chernova, O.V.; Zhukovin, S.V. Synthesis of $\mathrm{Ni}(\mathrm{II})$-Ti(IV) layered double hydroxides using coprecipitation at high supersaturation method. ARPN J. Eng. Appl. Sci. 2018, 13, 9652-9656.

48. Hansen, D.A.; Traut, D.E.; Fisher, G.T. Extraction of titanium and iron from ilmenite with fluosilicic acid. In Report of Investigations; United States Bureau of Mines: Washington, DC, USA, 1995; pp. 1-6.

49. Biswas, R.K.; Mondal, M.G.K.A. Study on the dissolution of ilmenite sand. Hydrometallurgy 1987, 17, $385-390$. [CrossRef]

50. Hansen, D.A.; Traut, D.E. The kinetics of leaching rock ilmenite with hydrofluoric acid. Mater. Appl. Serv. Exp. 1989, 41, 34-36. [CrossRef]

51. Laptash, N.M.; Maslennikova, I.G. Fluoride processing of titanium-containing minerals. Adv. Mater. Phys. Chem. 2012, 2, 21-24. [CrossRef] 
52. Laptash, N.M.; Maslennikova, I.G.; Kurilenko, L.N.; Mishchenko, N.M. Ilmenite fluorination by ammonium hydrodifluoride. New ammonium oxofluorotitanate. Russ. J. Inorg. Chem. 2001, 46, 28-34.

53. Adhyapak, S.V.; Wani, B.N.; Rao, U.R.K.; Kulshreshtha, S.K. Reactions of ammonium hydrogen fluoride with oxides of iron in solid state. Synth. React. Inorg. Met.-Org. Chem. 1992, 22, 337-348. [CrossRef]

54. Gordienko, P.S.; Dostovalov, V.A.; Pashnina, E.V. Hydrofluoride method of complex processing of titanium-containing raw materials. Solid State Phenom. 2017, 265, 542-547. [CrossRef]

55. Maslennikova, I.G. Influence of the amount of ammonium hydrogen difluoride on the degree of fluorination of mineral raw materials. Russ. J. Appl. Chem. 2009, 82, 1333-1337. [CrossRef]

56. Hiraki, T.; Maruyama, Y.; Suzuki, Y.; Itoh, S.; Nagasaka, T. Up-grading of natural ilmenite ore by combining oxidation and acid leaching. Int. J. Miner. Metall. Mater. 2018, 25, 729-736. [CrossRef]

57. Jabloski, M.; Przepiera, A. Kinetic model for the reaction of ilmenite with sulphuric acid. J. Therm. Anal. Calorim. 2001, 65, 583-590. [CrossRef]

58. Jabłonski, M. Influence of particle size distribution on thermokinetics of ilmenite with sulphuric acid reaction. J. Therm. Anal. Calorim. 2009, 96, 971-977. [CrossRef]

59. Nikolenko, N.V.; Kalashnikova, A.N.; Samchilev, I.S.; Kalashnikov, Y.V.; Kachalova, A.S. The model of the contracting core in the study of heterogeneous chemical processes in the L-S system. Vopr. Khimii i Khimicheskoi Tekhnologii 2015, 2, 103-119. (In Russian)

60. Jablonski, M.; Lawniczak-Jablonska, K.; Klepka, M.T. Investigation of phase composition of ilmenites and influence of this parameter on thermokinetics of reaction with sulphuric acid. J. Therm. Anal. Calorim. 2012, 109, 1379-1385. [CrossRef]

61. Goroschenko, Y.G.; Belyakova, E.P.; Kozachek, N.N.; Dvernyakova, A.A. Tehnicheskaya Dvuokis Titana i ee Poluchenie iz Izmenennogo Ilmenita Sernokislotnyim Metodom [Technical Titanium Dioxide and Its Preparation from Altered Ilmenite by the Sulfuric Acid Method]; Naukova Dumka: Kyiv, Ukraine, 1968; p. 94. (In Russian)

62. Liang, B.; Li, C.; Zhang, C.; Zhang, Y. Leaching kinetics of Panzhihua ilmenite in sulfuric acid. Hydrometallurgy 2005, 76, 173-179. [CrossRef]

63. Chun, L.; Bin, L.; Ling-hong, G.; Zi-bin, W. Effect of mechanical activation on the dissolution of Panzhihua ilmenite. Miner. Eng. 2006, 19, 1430-1438. [CrossRef]

64. Nikolenko, N.V.; Dubenko, A.V.; Vashkevich, E.Y.; Dmitrikova, L.V. Temperature optimum of the process of the dissolution of altered ilmenite in sulfuric acid. Voprosy khimii i hkimicheskoy tehnologii 2018, 3, 70-78. (In Russian)

65. Nikolenko, N.V.; Samchilev, I.S.; Kalashnikova, A.N.; Ananchenko, B.A. Thermodynamic and Kinetic Analyses of the Decomposition of Iron Molybdate with Soda Ash Solutions. Russ. J. Appl. Chem. 2015, 88, 208-215. [CrossRef]

66. Zhang, S.; Nicol, M.J. Kinetics of the dissolution of ilmenite in sulfuric acid solutions under reducing conditions. Hydrometallurgy 2010, 103, 196-204. [CrossRef]

67. Kalashnykov, Y.V.; Nikolenko, N.V.; Kachalova, A.S.; Dubenko, A.V.; Abramova, A.M. Effect of mechanical activation of malyshevsky ilmenite on its phase composition and leaching rate. Voprosy khimii i hkimicheskoy tehnologii 2015, 5, 57-69. (In Russian)

68. Nikolenko, N.V.; Dubenko, A.V.; Suschinskii, A.D.; Kalashnikov, Y.V. Decomposition of altered ilmenite by sulphuric acid. Vopr. Khimii i Khimicheskoi Tekhnologii 2016, 4, 55-62. (In Russian)

69. Koch, W.; Holthausen, M.C. A Chemist's Guide to Density Functional Theory; Wiley-VCH Verlag GmbH: Weinheim, Germany, 2001; p. 300.

70. Schuchardt, K.L.; Didier, B.T.; Elsethagen, T. Basis set exchange: A community database for computational sciences. J. Chem. Inf. Model 2007, 47, 1045-1052. [CrossRef] [PubMed]

71. Phoohinkong, W.; Pavasupree, S.; Wannagon, A.; Sanguanpak, S. Characterization and x-ray absorption spectroscopy of ilmenite nanoparticles derived from natural ilmenite ore via acidassisted mechanical ball-milling process. Adv. Nat. Sci. Nanosci. Nanotechnol. 2017, 8, 1-8. [CrossRef]

72. Dubenko, A.V.; Nikolenko, M.V.; Aksenenko, E.V.; Kostyniuk, A.; Likozar, B. Mechanism, Thermodynamics and Kinetics of Rutile Leaching Process by Sulfuric Acid Reactions. Processes 2020, 8, 640. [CrossRef]

(C) 2020 by the authors. Licensee MDPI, Basel, Switzerland. This article is an open access article distributed under the terms and conditions of the Creative Commons Attribution (CC BY) license (http://creativecommons.org/licenses/by/4.0/). 